\title{
Corrosion Protection of Metallic Waste Packages Using Thermal Sprayed Ceramic Coatings
}

\author{
K.R. Wilfinger \\ J.C. Farmer \\ R.W. Hopper \\ T.E. Shell
}

This paper was prepared for submittal to the

Materials Research Society 1998 Fall Meeting

Boston, MA

November 30-December 4, 1998

November 1998

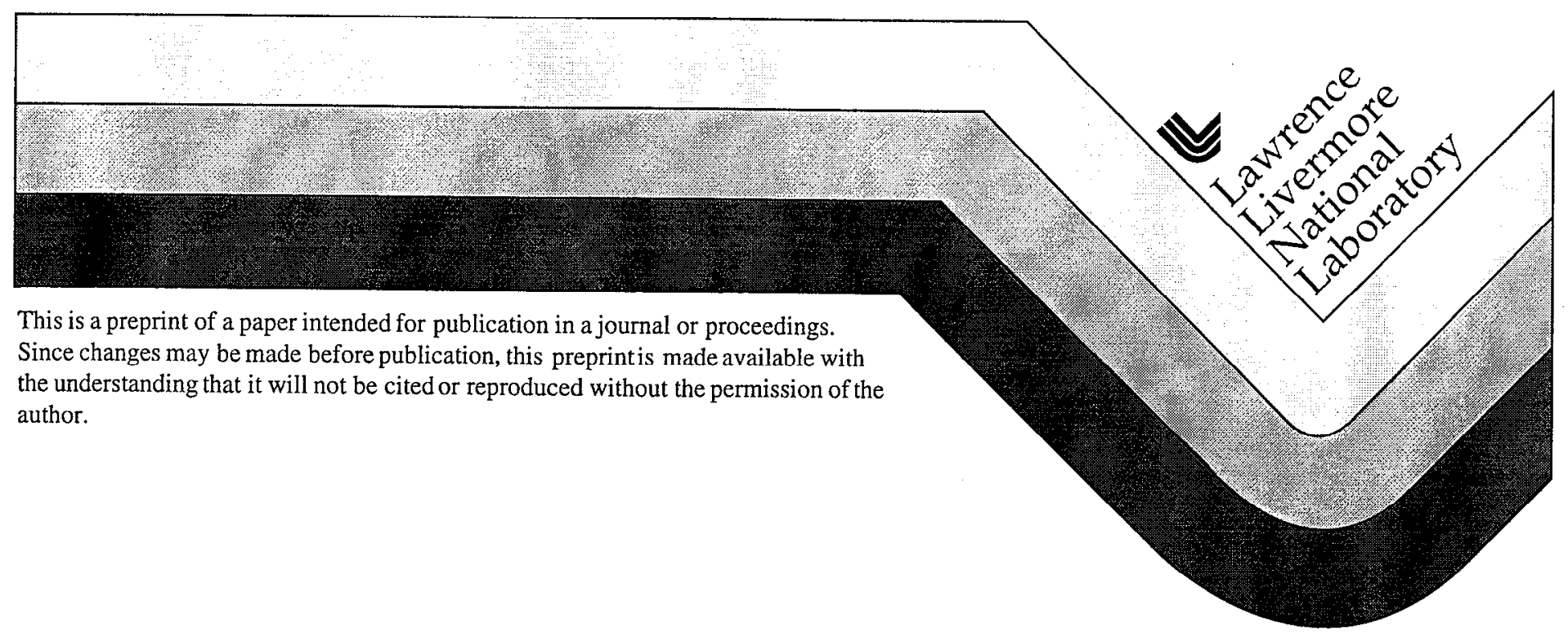




\section{DISCLAIMER}

This document was prepared as an account of work sponsored by an agency of the United States Government. Neither the United States Government nor the University of California nor any of their employees, makes any warranty, express or implied, or assumes any legal liability or responsibility for the accuracy, completeness, or usefulness of any information, apparatus, product, or process

disclosed, or represents that its use would not infringe privately owned rights. Reference herein to any specific commercial product, process, or service by trade name, trademark, manufacturer, or otherwise, does not necessarily constitute or imply its endorsement, recommendation, or favoring by the United States Government or the University of California. The views and opinions of authors expressed herein do not necessarily state or reflect those of the United States Government or the University of California, and shall not be used for advertising or product endorsement purposes. 


\title{
CORROSION PROTECTION OF METALLIC WASTE PACKAGES USING THERMAL SPRAYED CERAMIC COATINGS
}

\author{
K.R. Wilfinger, J.C. Farmer, R.W. Hopper and T.E. Shell \\ ${ }^{*}$ Lawrence Livermore National Lab, P.O. Box 808, L-355, Livermore, CA 94550
}

\begin{abstract}
Ceramic coated carbon steel coupons were corrosion tested in water with dissolved salts to simulate exposure to evaporation concentrated groundwater in an underground nuclear repository. Metallography revealed no corrosion at the ceramic metal interface of dense coatings, even though electrical measurements demonstrated that the coatings were slightly porous. Experimental results and a model to predict corrosion rates influenced by a porous ceramic coating and coating lifetimes are presented.
\end{abstract}

\section{INTRODUCTION}

Certain refractory ceramic oxides have desirable properties for the construction of containers for long-term use in nuclear waste disposal applications such as the proposed Yucca Mountain repository. Ceramics are thermodynamically stable against further oxidation and far less prone to environmental corrosion than metals under realistic repository conditions. The aqueous corrosion rates of oxides such as spinel $\left(\mathrm{MgAl}_{2} \mathrm{O}_{4}\right)$, alumina $\left(\mathrm{Al}_{2} \mathrm{O}_{3}\right)$ and titania $\left(\mathrm{TiO}_{2}\right)$, fall in the range of a few millimeters per million years. Oxide ceramics are unlikely to be subject to microbiologically influenced corrosion (MIC), which may attack most, if not all, of the available engineering metals over time.

Ceramics have a reputation for poor mechanical performance, and sufficiently large, impermeable vessels are not easily fabricated in large numbers. Current waste package designs are based on multiple metallic layers to provide handling capability and "defense in depth" because of varying corrosion mechanisms between layers. The most promising approach for incorporating ceramics in large waste packages is as a low porosity protective coating to a supporting metallic structure, such as the steel "corrosion allowance material" (CAM) that has been part of the primary design focus of the Yucca Mountain Project (YMP). Coatings applied by thermal-spray can be effectively seamless and offer a method for final closure of the package while maintaining low average temperatures within the waste package.

Without liquid or vapor phase water, electrochemical corrosion and MIC processes are considered impossible, so an impervious ceramic coating should protect the metal vessels indefinitely. Even an imperfect coating should extend the life of the package, delaying the onset and reducing the severity of corrosion by limiting the transport of water and oxygen to the ceramic-metal interface. Logically, if the oxygen transport is impeded, the corrosion rate will decrease. There is a presumption that all thermal sprayed coatings will be porous at some level, so the model which follows is an attempt to account for increased impedance to oxygen transport due to a porous coating and predict a resulting corrosion rate.

\section{EXPERIMENT}

Porous (19\% porous) alumina coatings were produced on cylindrical steel substrates using conventional plasma spray. Higher density alumina, titania and spinel coatings were manufactured via high velocity oxy-fuel (HVOF) spraying ( $2 \%$ porous) and detonationspraying ( $6 \%$ porous). Coatings up to 1.5 millimeters thick were tested. Some coatings were applied over a bond coat of a nickel-based alloy. Optical and SEM metallography of sample cross sections demonstrate the morphology of the various coating types. Image analysis was used to estimate the total fraction of porosity.

Apparently circular pores might be elongated pores revealed in cross section. Radial separations (microcracks or pores) appear to be submicron in thickness and a few microns long. 
Rounded inclusions are particles which apparently melted but solidified before impact and sharp-edged inclusions are unmelted particles trapped in the coating.
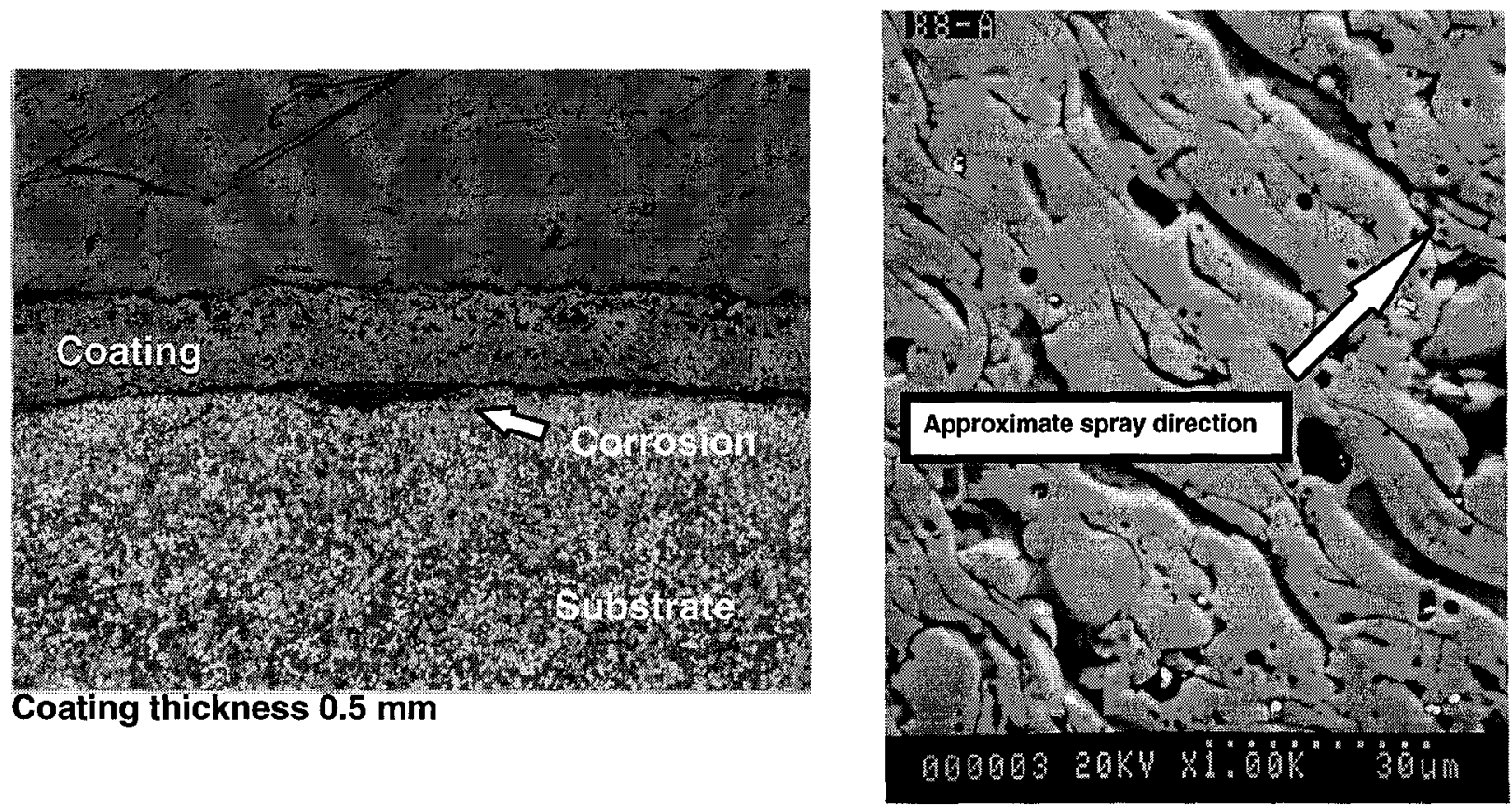

Figure 1: Optical and SEM micrographs of a low-density ( $19 \%$ porous) plasma sprayed coating after 6 month exposure to simulated concentrated J-13 well water at $90^{\circ} \mathrm{C}$.
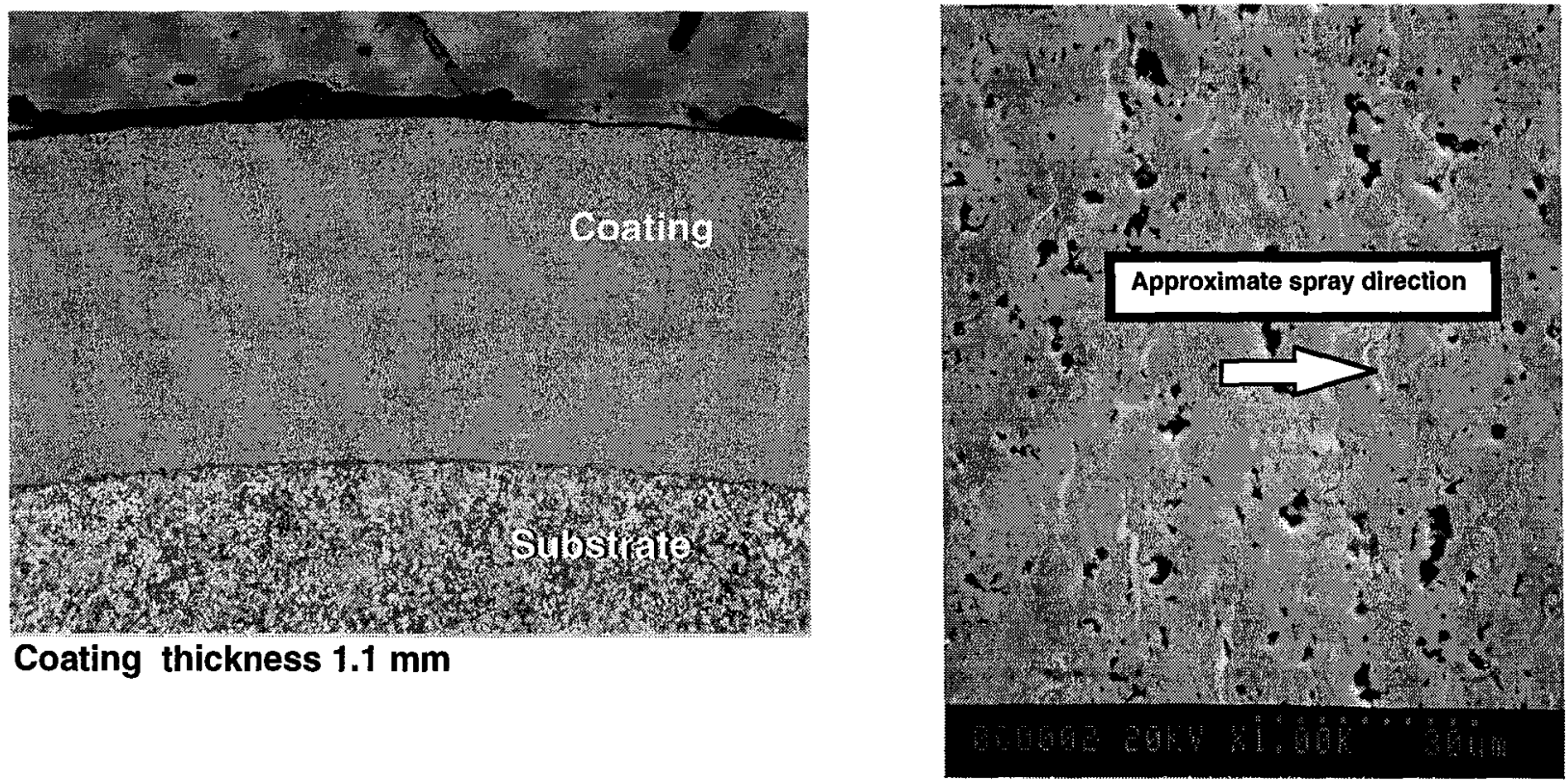

Figure 2: Optical and SEM micrographs showing the structure of a high density HVOF coating after 6 months exposure in simulated concentrated $\mathrm{J}-13$ water at $90^{\circ} \mathrm{C}$. 


\section{Corrosion Testing}

Corrosion testing was carried out in stirred baths containing simulated $10 \times$ concentrated, $\mathrm{J}-13$ well water at $90^{\circ} \mathrm{C}$ (total dissolved solids $\sim 1500 \mathrm{ppm}$, pH between 10.0 and 10.2). Samples straddled the water line, exposing them to water, oxygen, and deposited salts. Some were put in whole and some were slotted in two places (above and below the water line) to induce local corrosion. Samples were withdrawn from the baths at 3 month intervals for examination. Slotted regions were filled with epoxy to trap any corrosion products which might be present prior to sectioning.

A

\section{$\mathbf{B}$}
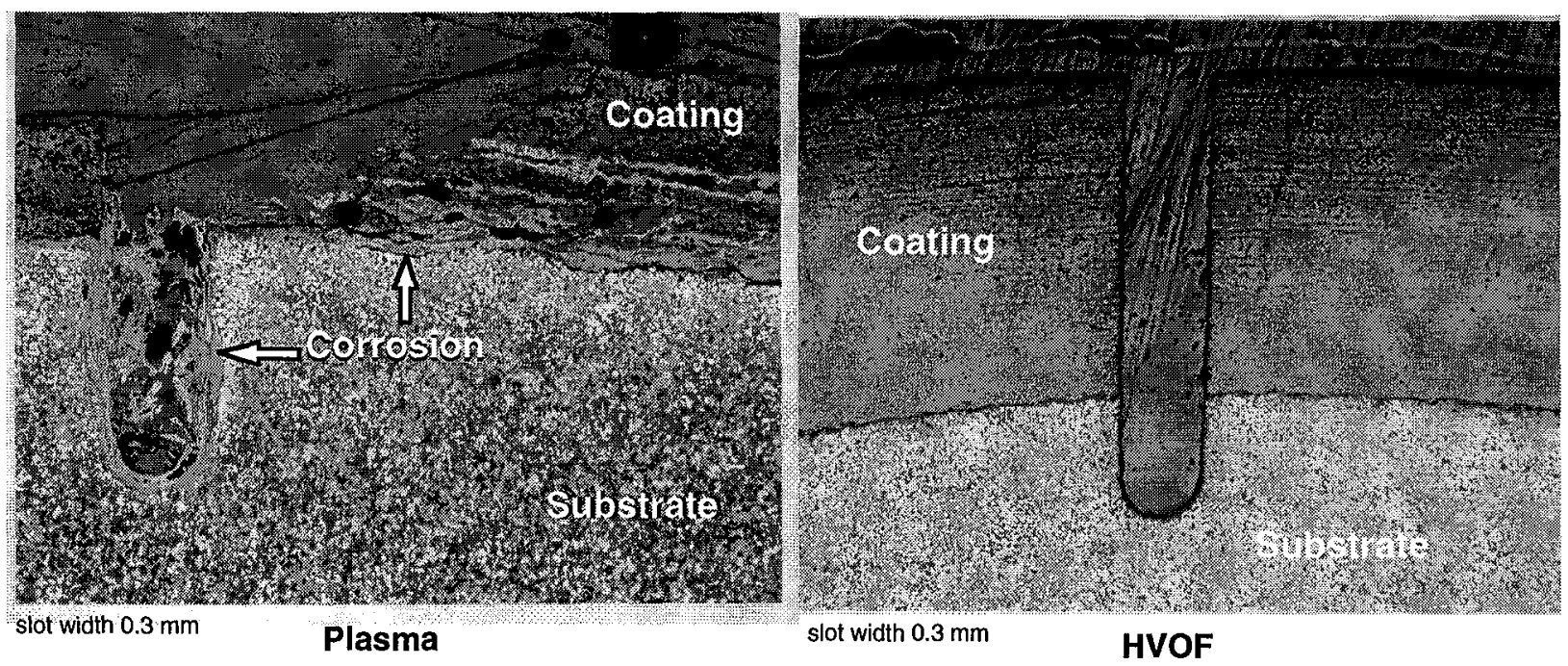

Figure 3: (A) Plasma sprayed coating ( $19 \%$ porosity) and (B) Dense HVOF ( $2 \%$ porosity) coatings exposed to simulated concentrated $\mathrm{J}-13$ well water at $90^{\circ} \mathrm{C}$ for 6 months.

\section{AC Impedance Spectroscopy}

Simple contact conductivity (DC resistance) measurements conducted in salt water demonstrated that a conductive pathway to the substrate could be established quickly for all coatings, verifying the presence of interconnected porosity. AC impedance spectroscopy using a potentiostat was performed on several variations of thermal-sprayed samples immersed in $1000 x$ concentrated, simulated J-13 water ( $130,000 \mathrm{ppm}$ dissolved solids).

Since conductivity through liquid-filled channels is directly related to the ease with which ionic species (including dissolved oxygen) can pass through the channels, the electrical impedance measured at very low frequencies should correspond directly to the impedance of oxygen transport from the outside to the substrate, whereas the impedance at very high frequencies is primarily due to ionic conductivity of the electrolytes in the pores. At high frequencies, there is electrical conductivity due to charge transfer, but one can picture the ions themselves merely oscillating in place, so that there would still be reduced net transport of oxygen.

At low frequencies (around $10 \mathrm{~Hz}$ ), the electrochemical impedance was found to be increased by eight orders of magnitude for HVOF and detonation coatings, corresponding to a reduction of the corrosion rate of the substrate by eight orders of magnitude $\left(\times 10^{8}\right)$. The reduction in corrosion rate can be explained by impeded oxygen transport through the electrolyte in the pores as well as by an increase in the interfacial impedance due to blockage by the coating. Results are in general agreement with the lack of corrosion observed beneath dense coatings. The plasma sprayed coating had little effect on the measured impedance or apparent corrosion rate because its $19 \%$ porosity was highly interconnected. 


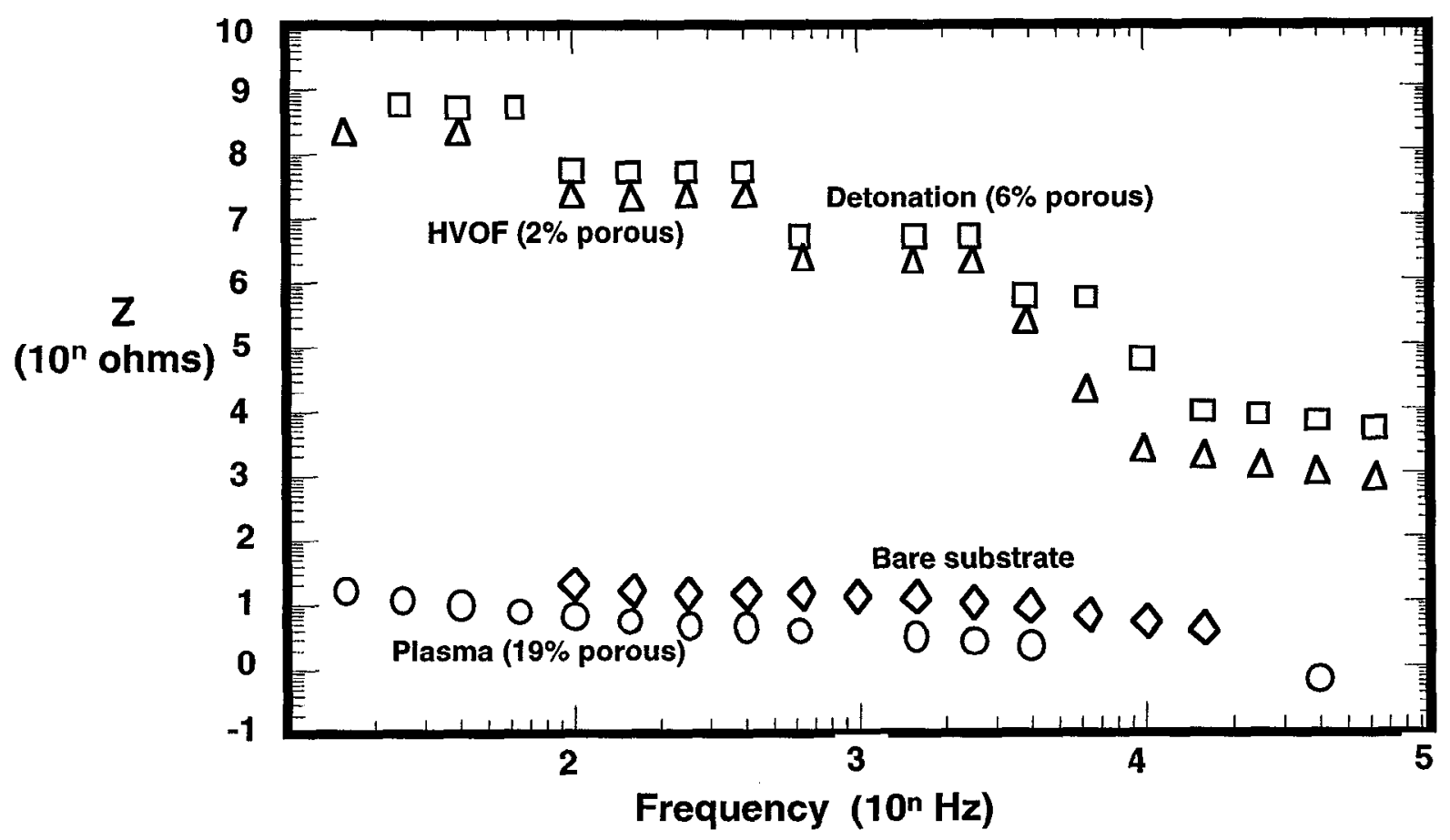

Figure 4: AC impedance measurements on ceramic coated substrates immersed in simulated 1000x concentrated J-13 well water

\section{MODEL FOR INHIBITION OF CAM CORROSION BY A POROUS COATING [1]}

\section{Dry Oxidation}

The impedance to gas-phase transport of oxygen is relatively insignificant, but so is the corrosion. A good approximation is the dry oxidation rate provided by Henshall [2]:

$$
x_{\mathrm{ox}}(t)^{2}=x_{\mathrm{ox}}\left(t_{0}\right)^{2}+2 k_{\mathrm{p}} \int_{t_{0}}^{t} \exp [-Q / R T(t)] d t
$$

where $k_{\mathrm{p}}=4.3 \times 10^{-5} \mathrm{~cm}^{2} / \mathrm{s}, Q=104 \mathrm{~kJ} / \mathrm{mol}$, and $R=8.314 \mathrm{~J} / \mathrm{mol}$. The ratio of metal penetration to oxide thickness, $\beta$, is 0.48 . This predicts an oxide thickness of approximately $6.24 \mu \mathrm{m}$ after 1000 years of dry oxidation at $150^{\circ} \mathrm{C}$.

\section{Pores Partially Filled with Moisture}

The corrosion rate is assumed to be limited by the corrosion layer formed at the airmetal interface at the base of pores. Typical HAC rates apply $(60 \%<R H<80 \%$ and no dripping). Gas-filled pores assumed not to significantly impede the rate of HAC. At a penetration rate of $10 \mu \mathrm{m} / \mathrm{y}$, it should take several thousand years to reach the fracture strain of the coating. The environment is predicted to transition to saturated conditions $(80 \%<R H$ and dripping water) long before fracture occurs.

\section{Pores Completely Filled with Moisture}

Typical aqueous-phase corrosion rates apply at the ceramic-metal interface $(80 \%<R H$ and dripping condition). The flux of oxygen $N_{\mathrm{A}}$ through multiple diffusion barriers, phases $\mathrm{P}$ and $Q$ is defined by: 


$$
N_{\mathrm{A}}=K_{\mathrm{P}}\left(a_{\mathrm{PB}}-a_{\mathrm{Pi}}\right)=K_{\mathrm{Q}}\left(a_{\mathrm{Qi}}-a_{\mathrm{QB}}\right)=K_{\mathrm{a}}\left(a_{\mathrm{PB}}-a_{\mathrm{QB}}\right) .
$$

The overall mass-transfer coefficient (mass-transfer resistance) can be expressed in terms of individual mass-transfer coefficients for phases $P$ and $Q \quad[3]$ :

$$
\frac{1}{K_{A}}=\frac{1}{K_{P}}+\frac{1}{K_{Q}}
$$

Pores are treated as long cylinders of length $\delta$, where:

$$
N_{\mathrm{A}}=\frac{D_{\mathrm{A}}}{\delta}\left(a_{\mathrm{PB}}-a_{\mathrm{Pi}}\right) \text {. }
$$

The average flux of oxygen per unit area of waste package is then:

$$
\overline{N_{\mathrm{A}}}=\frac{\theta}{\delta} D_{\mathrm{A}}\left(a_{\mathrm{PB}}-a_{\mathrm{Pi}}\right),
$$

where $\theta$ is the fraction of the CAM exposed to the aqueous phase at the ceramic-CAM interface. This fraction $\theta$ is equivalent to the porosity in the coating. Values of $0.02-0.03$ have been achieved with HVOF. The overall mass-transfer coefficient is then:

$$
\frac{1}{K}=\frac{1}{K_{0}}+\frac{1}{K_{I}}=\frac{1}{K_{0}}+\frac{\delta}{\theta D_{A}} \quad \text { or } \quad K=\frac{1}{\frac{1}{K_{0}}+\frac{\delta}{\theta D_{A}}}
$$

A factor $g$ to correct the oxygen-limited corrosion rate for the presence of a porous ceramic barrier can be defined as:

$$
g=\frac{\overline{N_{\mathrm{A}}}}{\overline{N_{\mathrm{A}, 0}}}=\frac{\frac{1}{K_{0}}}{\frac{1}{K_{0}}+\frac{\delta}{\theta D_{A}}}=\frac{1}{1+\frac{K_{0 \delta}}{\theta D_{A}}} .
$$

This correction factor assumes simple cylindrical pores, which is unrealistic. The pores in real coatings more closely resemble an array of chains, each link composed of a hollow sphere which dominates the apparent pore volume and a relatively narrow hollow cylinder which dominates the impedance, connected in series. In such a case, the mass-transfer coefficient for the ceramic coating, $K_{\mathrm{I}}$, should be reduced by a factor $f(\varepsilon, \lambda)$, which accounts for the geometry. Thus: $K_{\mathrm{I}, \text { corrected }}=f(\varepsilon, \lambda) \times K_{\mathrm{I}}$. We define $f(\varepsilon, \lambda)$ as:

$$
f(\varepsilon, \lambda)=\frac{3}{2} \frac{(1+\lambda)^{2}}{\lambda} \varepsilon^{2}
$$

The dimensionless parameters $\varepsilon$ and $\lambda$ represent the geometry of the sphere-cylinder chain where:

$$
\varepsilon=\frac{\text { diameter of cylinder }}{\text { diameter of sphere }} \text { and } \lambda=\frac{\text { length of cylinder }}{\text { diameter of sphere }} \text {. }
$$

Current estimates for $\varepsilon$ based on observed microstructures vary from a low of 0.01 or 0.03 to a high of 0.05 (worst case). Estimates for $\lambda$ range from a minimum of 5 to a maximum of 30 , with 10 considered a representative value. A range of $f(0.03,10)=0.016$ to $f(0.05,10)=0.045$ is therefore considered reasonable. 
As an example, we estimate $f(\varepsilon, \lambda)$ to be approximately 0.03 , which is mid-range. Given this model, the modified factor used to correct the oxygen-limited corrosion rate is:

$$
g_{\text {corrected }}=\frac{1}{1+\left(\frac{K_{0} \delta}{\theta D_{A}}\right)\left(\frac{1}{f(\varepsilon, \lambda)}\right)}
$$

\section{Corrosion Calculations}

The stoichiometry assumed to exist between iron and oxygen is: $4 \mathrm{Fe}+3 \mathrm{O}_{2} \rightarrow 2 \mathrm{Fe}_{2} \mathrm{O}_{3}$. The relationship between the oxygen flux in a single pore, $N_{\mathrm{A}}$, and the corrosion rate $d p / d t$ can be written as:

$$
3 N_{\mathrm{A}, 0}=3 K_{0}\left(C_{\text {oxygen }}\right)=4 \frac{\rho}{w} \frac{d p}{d t},
$$

where $w$ is the atomic weight $(55.847 \mathrm{~g} / \mathrm{mol})$ and $\rho$ is the density $\left(7.86 \mathrm{~g} / \mathrm{cm}^{3}\right)$ of iron.

A conservative value of the aqueous-phase corrosion rate is taken as a basis for calculating the apparent mass-transfer coefficient representing corrosion in the absence of a coating:

$$
\frac{d p}{d t} \approx 300 \frac{\mu \mathrm{m}}{\mathrm{y}}=\frac{300 \times 10^{-4}}{365 \times 24 \times 3600} \frac{\mathrm{cm}}{\mathrm{s}}=9.513 \times 10^{-10} \frac{\mathrm{cm}}{\mathrm{s}} .
$$

This represents six-month data from the Long Term Corrosion Test Facility (LTCTF) at LLNL reported by Farmer [4]. The concentration of oxygen dissolved in water (equilibrium with ambient air) at the air-ceramic interface is $C_{\text {oxygen }}=2.56 \times 10^{-7} \mathrm{~mol} / \mathrm{cm}^{3}$. The flux of oxygen associated with this mass-transfer coefficient is then:

$$
N_{\mathrm{A}, 0}=\left(\frac{4}{3}\right) \frac{7.86 \times 9.513 \times 10^{-10}}{55.847} \frac{\mathrm{mol}}{\mathrm{cm}^{2} \mathrm{~s}}=\left(\frac{4}{3}\right) 1.339 \times 10^{-10} \frac{\mathrm{mol}}{\mathrm{cm}^{2} \mathrm{~s}}=1.785 \times 10^{-10} \frac{\mathrm{mol}}{\mathrm{cm}^{2} \mathrm{~s}} \text {. }
$$

The mass-transfer coefficient in the absence of a ceramic barrier is :

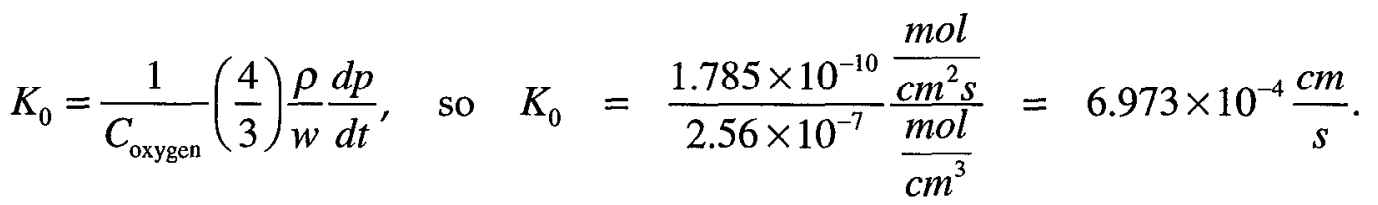

The factor to correct the corrosion rate for the presence the coating is then:

$$
g_{\text {corrected }}=\frac{1}{1+\frac{(0.15 \mathrm{~cm})\left(6.973 \times 10^{-4} \mathrm{~cm} / \mathrm{s}\right)}{(0.02)\left(10^{-5} \mathrm{~cm}^{2} / \mathrm{s}\right)(0.03)}}=5.736 \times 10^{-5}
$$

The $2 \%$ porous ceramic coating would lower the aqueous-phase corrosion rate from approximately $300 \mu \mathrm{m} / \mathrm{y}$ to only $8.602 \times 10^{-2} \mu \mathrm{m} / \mathrm{y}$.

$$
\frac{d p}{d t}=g_{\text {corrected }}\left(\frac{d p}{d t}\right)_{0}=1.721 \times 10^{-2} \frac{\mu \mathrm{m}}{\mathrm{y}}
$$




\section{Time to Fracture}

The time to first coating fracture due to the formation of corrosion products at the ceramic-CAM interface can be estimated, provided that the mechanical properties of the ceramic are known. Estimated properties for ceramics taken from the literature [5] are summarized in Table 1:

Table 1. Mechanical Properties of Ceramic Coatings

\begin{tabular}{|l|l|l|l|l|}
\hline Property & $\begin{array}{l}\text { Elastic modulus } \\
(E)\end{array}$ & $\begin{array}{l}\text { Elastic modulus } \\
(E)\end{array}$ & $\begin{array}{l}\text { Fracture } \\
\text { strength }(\sigma)\end{array}$ & $\begin{array}{l}\text { Fracture } \\
\text { strength }(\sigma)\end{array}$ \\
\hline Units & $\mathrm{MPa}$ & $\mathrm{Mpsi}$ & $\mathrm{MPa}$ & $\mathrm{kpsi}$ \\
\hline $\mathrm{Al}_{2} \mathrm{O}_{3}$ & 365,000 & 53 & 172 & 25 \\
\hline $\mathrm{ZrO}_{2}$ & 144,900 & 21 & 55 & 8 \\
\hline
\end{tabular}

Fracture toughness values observed for typical ceramics range from $K_{\mathrm{IC}}=3.3$ to $5.8 \mathrm{MPa} \cdot \mathrm{m}^{1 / 2}$ or 3.0 to $5.3 \mathrm{kpsi} \cdot \mathrm{in}^{1 / 2}$.

The rate of expansion of the inner radius of the ceramic barrier coating is estimated from. the penetration rate, accounting for expansion at the interface due to the density difference between $\mathrm{Fe}_{2} \mathrm{O}_{3}$ and Fe:

$$
\frac{d R}{d t}=2 \frac{d p}{d t}=2 \times 1.721 \times 10^{-2} \frac{\mu \mathrm{m}}{\mathrm{y}}=3.442 \times 10^{-2} \frac{\mu \mathrm{m}}{\mathrm{y}}=3.442 \times 10^{-8} \frac{\mathrm{m}}{\mathrm{y}} .
$$

Given the inner radius of the waste package, $R=1 \mathrm{~m}$, the strain rate in the ceramic coating can be estimated as:

$$
\frac{d e}{d t}=\frac{1}{2 \pi R} 2 \pi \frac{d R}{d t}=3.442 \times 10^{-8} \frac{1}{\mathrm{y}} .
$$

The relationship between the stress and strain is: $\sigma=E \times e$. The fracture strain can then be estimated from the elastic modulus and the fracture stress:

$$
e^{*}=\frac{\sigma^{*}}{E}=\frac{172 \mathrm{MPa}}{356,000 \mathrm{MPa}}=4.831 \times 10^{-4} \text {. }
$$

The time for the strain to reach the fracture strain determines the time to fracture:

$$
\tau *=\frac{e^{*}}{d e / d t}=\frac{4.831 \times 10^{-4}}{3.442 \times 10^{-8}} y=14,037 \mathrm{y} .
$$

The critical flaw size for crack initiation is estimated as:

$$
a^{*} \approx\left(\frac{K_{\mathrm{IC}}}{\sigma^{*}}\right)^{2} \frac{1}{\pi}=\left(\frac{3.3 \mathrm{MPa} \sqrt{m}}{172 \mathrm{MPa}}\right)^{2} \frac{1}{\pi}=1.172 \times 10^{-4} \mathrm{~m}=117.2 \mu \mathrm{m},
$$

where the fracture toughness is defined as $K_{\mathrm{IC}}=\sigma \cdot(\pi a)^{3 / 2} \cdot f(a, W)$.

Important physical considerations inherent to this model include:

- The substrate corrosion mechanisms are not changed by the presence of the coating, only slowed by reduced transport rates. If a substantial portion of the coating simply disappeared, the situation would be no worse than without a coating. 
- The model treats the coating as an isotropic continuum and treats the waste package in its entirety to predict the onset of the first crack. The formation of a single crack would not actually constitute total failure and removal of the coating, but it could tend to relieve stresses that might lead to further cracking.

- The model calculation is highly sensitive to the values assigned to the pore parameters, especially the cylinder diameters. The example pore dimensions used to illustrate the model were not rigorously determined so the explicit results can not yet be considered accurate.

- The impedance to oxygen transport imposed by a porous coating depends on whether the pores are filled with liquid, gas, or an appropriate sealant. The $g$-factor for dry oxidation was assumed to be unity due to unsealed, gas-filled porosity. The ceramic was ignored for purposes of calculating dry oxidation, even though about $98 \%$ of the substrate surface is covered and the remainder is exposed only through long, convoluted, and narrow channels. The $g$-factor for aqueous-phase corrosion will necessarily be much smaller than this, due to reduced diffusion rates of oxygen through liquid-filled pores. The $g$-factor for the humid-air corrosion regime is a large source of uncertainty and is assumed to lie somewhere between the $g$-factor for dry oxidation and that for aqueous-phase corrosion.

\section{CONCLUSION}

A slightly porous ceramic coating will significantly lengthen the life of a steel container under saturated conditions, adding an estimated minimum of 14,037 years of life (Table 2). This estimate of the life extension due to the presence of the ceramic coating does not explicitly account for humid air corrosion or dry oxidation. Waste package life might be further extended by taking steps to close interconnected porosity in the ceramic coating by control of pore morphology and total pore fraction or by using sealants.

Table 2. Extension of Waste-Package Life with Ceramic Coating

\begin{tabular}{|l|l|l|}
\hline & Life with ceramic coating $(y)$ & Life without ceramic coating $(y)$ \\
\hline Thermal pulse & $\sim 1,000$ & $\sim 1,000$ \\
\hline Ceramic barrier & $>14,037$ & 0 \\
\hline CAM - after exfoliation & $>333$ & $>333$ \\
\hline
\end{tabular}

\section{ACKNOWLEDGEMENTS}

Work performed under the auspices of the U.S. Department of Energy by the Lawrence Livermore National Laboratory under Contract W-7405-ENG-48. Work supported by the Yucca Mountain Site Characterization Project.

\section{REFERENCES}

1. Hopper, R., J.C. Farmer, and K. Wilfinger. "Summary of Model to Account for Inhibition of CAM Corrosion by Porous Ceramic Coating." (UCRL-ID-130502): Lawrence Livermore National Laboratory, Livermore, CA, 1998.

2. Henshall, G.A., "Numerical Predictions of Dry Oxidation of Iron and Low-Carbon Steel at Moderately Elevated Temperatures." (UCRL-JC-124639) Lawrence Livermore National Laboratory, Livermore, CA,1996.

3. Sherwood, T.K., P.L. Pigford, and C.R. Wilke, Mass Transfer, McGraw-Hill, San Francisco, CA, 1975 pp. 178-182.

4. Farmer, J.C. "Development of corrosion models for high-level waste containers." In proceedings of the Sixth Inlernational Conference on Nuclear Engineering (ICONE-6). San Francisco, May 10-14, 1998. ASME. 13 p.

5. Thornton, P.A., and V.J. Colangelo (1985). Fundamentals of Engineering Materials. Prentice Hall, Englewood Cliffs, NJ, 1985. 


\section{Corrosion Protection of Metallic Waste Packages Using Thermal Sprayed Ceramic Coatings}

K. R. Wilfinger, J. C. Farmer, R. W. Hopper, and T. E. Shell

Lawrence Livermore National Laboratory, P.O. Box 808, L-355, Livermore, CA 94550
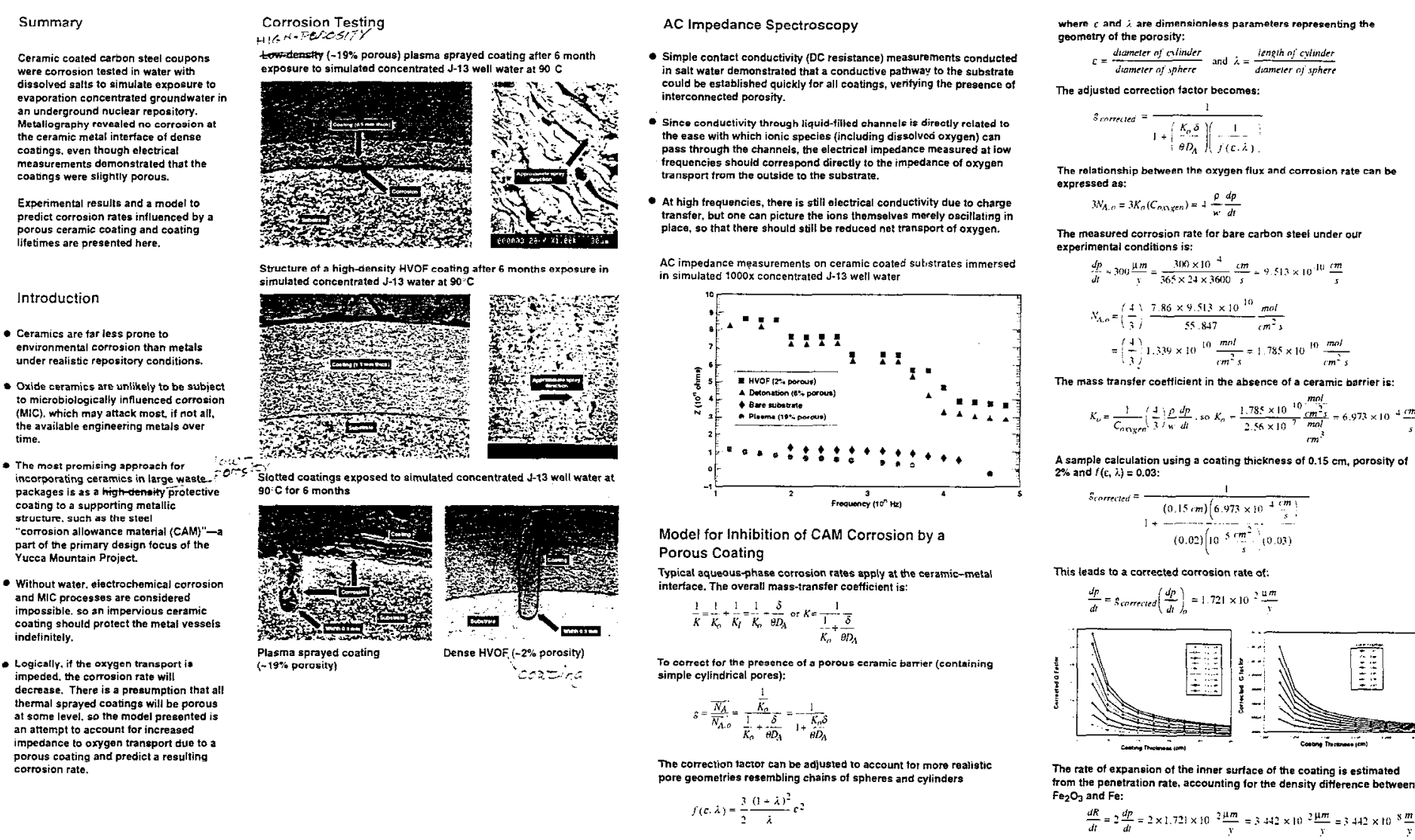

AC Impedance Spcctroscopy

- Simple contact conductiviry (DC resistance) measurements conducted

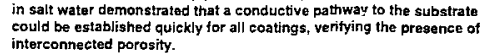

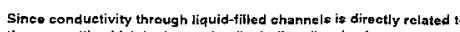

trom the outsise to th the sustratate.

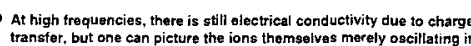
place, so that there should sill be reduced not transport of oxygen.

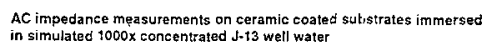

Model for Inhibition of CAM Corrosion by a

Porous Coating

Typical oqueous-phase corrosion ratas apply at the ceramic-metal
interface. The overall masss-ranster coetficient is:$$
\frac{1}{K}=\frac{1}{K_{p}}+\frac{1}{K_{i}}=\frac{1}{K_{B}}-\frac{s}{\theta D_{A}} \text { or } K=\frac{1}{\frac{1}{K_{i}}+\frac{\bar{\delta}}{\partial D_{A}}}
$$

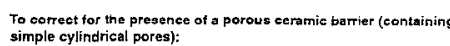

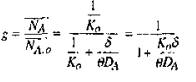

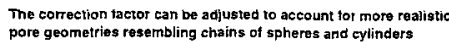
$f(c, i)-\frac{3}{2} \frac{(1+i)^{2}}{i}-\varepsilon^{2}$

This leads to a corrected corrosion rate of: Tho rate of expansion of the inner surrace of the coating is estimated
trom the pentetration rate, accounting tor the density ditierence between

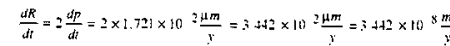

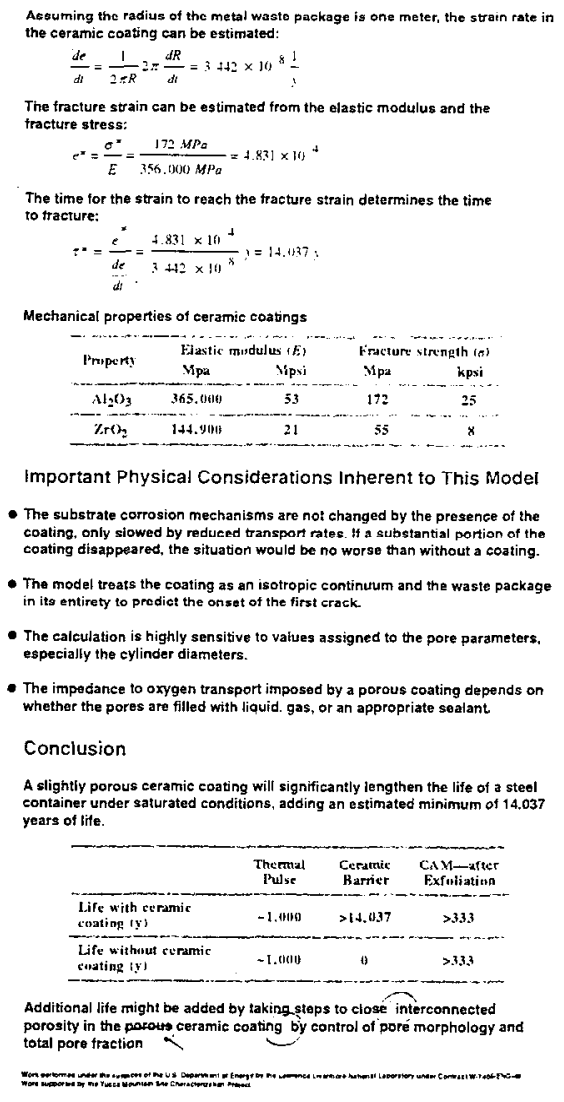

